\title{
The validity and reliability of the Healthy Lifestyle Screening Tool
}

\author{
Cheong Hoon Kim ${ }^{a}$, Kyung-Ah Kang ${ }^{\mathrm{b}}$ \\ ${ }^{a}$ Department of Physical Therapy, Collage of Health Science and Social Welfare, Sahmyook University, Seoul, Republic of Korea \\ ${ }^{\mathrm{b}}$ College of Nursing, Sahmyook University, Seoul, Republic of Korea
}

Objective: The aim of the present study was to develop a valid and reliable scale that measures the healthy life styles among young adults.

Design: A methodological study design was employed to develop and validate the Healthy Lifestyle Screening Tool (HLST). Methods: The validity and reliability of the HLST were established in accordance with DeVellis' 8 steps guideline for tool development. The question items were generated based on literature reviews and interviews, which were then classified into 12 categories. The HLST was administered to 272 students attending a Korean university. The reliability was tested using Cronbach's alpha. The validity of the scale was examined with the mean inter-item correlations (MIIC) and factor analysis, and was also examined for content validity by experts.

Results: The reliability of the HLST was found to be acceptable, as indicated by a Cronbach's alpha of 0.71 . In the validity test, items with less than $80 \%$ "agreement" ratings on the content validity index by experts were revised. The MIIC values were greater than 0.25 . A factor analysis of 36 items extracted 9 factors (i.e., four items per factor), which together explained $50.4 \%$ of the variance. The HLST consists of 36 items that measure 9 factors based on a 4-point Likert rating scale, with 4 items per factor, as follows: sunlight, water, air, rest, exercise, nutrition, temperance, trust, and general physical condition. High scores on the HLST are indicative of a healthy lifestyle (HL).

Conclusions: The HLST is a valid and reliable scale that can be used to measure HL among young adults. Identification of HL by using the HLST can provide guidance to integrated therapeutic approaches along with conventional physical therapy.

Key Words: Adults, Health, Life style, Reliability, Validity

\section{Introduction}

Individuals differ in their lifestyle behaviors. Studies have found that a healthy lifestyle (HL) is significantly correlated with health maintenance and disease prevention [1-3]. Lifestyle can be defined as a person or group's way of living, such as specific behaviors or habits [4]. The World Health Organization's guidelines suggest that a HL can reduce the risk of preventable health problems and improve one's quality of life (QoL) [5]. A HL entails conscious efforts on part of the individual to effectively protect one's health and the health of others [6]. Healthcare professionals advise patients about the importance of a $\mathrm{HL}$ and its role in disease prevention and recovery. Moreover, various healthrelated articles have also posited that a HL plays a crucial role in averting the development of lifestyle diseases [7-10].

Physical therapists can effectively counsel patients about the importance of a HL, either individually or as a part of a health professional team. Most patients believe that it is necessary for them to have a therapeutic relationship with physical therapists and to speak to them about a HL. Moreover, they consider physical therapists to be their role models since they promote the health and wellbeing of their patients through exercise prescription [11]. Patients also believe that

Received: 16 May, 2019 Revised: 12 June, 2019 Accepted: 12 June, 2019

Corresponding author: Kyung-Ah Kang (ORCID https://orcid.org/0000-0002-3799-9554)

College of Nursing, Sahmyook University, 815 Hwarang-ro, Nowon-gu, Seoul 01795, Republic of Korea

Tel: 82-2-3399-1585 Fax: 82-2-3399-1594 E-mail: kangka@syu.ac.kr

(c) This is an Open-Access article distributed under the terms of the Creative Commons Attribution Non-Commercial License (http://creativecommons.org/licenses/ by-nc/4.0) which permits unrestricted non-commercial use, distribution, and reproduction in any medium, provided the original work is properly cited.

Copyright (๑ 2019 Korean Academy of Physical Therapy Rehabilitation Science 
physical therapists should advise them about various personal health-related behaviors. Therefore, physical therapists require a broad array of knowledge and skills that extend beyond traditional notions of physical therapy [12].

In order to ensure that physical therapy yields effective outcomes, first-line interventions must not only adopt the traditional approaches (e.g., exercise prescription) but should also promote a HL [12]. Individual physical activity levels, which comprise of the patient's dietary status and other unhealthy behaviors, should be assessed during the first and follow-up visits. However, HL related factors have not been assessed primarily due to the following reasons: lack of time, limited knowledge and expertise, traditional beliefs about the physical therapist's role (i.e., that assessing HR-related factors is not a physical therapist's responsibility), and patients' lack of interest in changing their unhealthy lifestyles [11]. Additionally, whereas physical therapists in the community rely heavily on their tacit and professional subject-matter knowledge, they often ironically believe that these skills do not pertain to physical therapy [9].

There is sufficient evidence to show that HL changes are needed to prevent injury or improve functional limitations. However, previous assessment tools have primarily dealt with only limited aspects of a HL, such as nutrition, exercise, and mindfulness [7-10]. There is lack of a lifestyle tool that includes information about a broad aspect of healthy lifestyle choices that could be completed in a relatively short period of time. The purpose of a screening tool is to guide and provide effective lifestyle advice based on the result of a HL in a timely manner. Therefore, the purpose of this study was to develop a valid and reliable screening tool to measure $\mathrm{HL}$ among adults.

\section{Methods}

\section{Research design}

This study employed a methodological design to develop the Healthy Lifestyle Screening Tool (HLST), which evaluates HL among young adults. The validity and reliability of the HLST were established in accordance with DeVellis' guidelines [13] for tool development (Figure 1).

\section{Participants}

In order to test the reliability and validity of a developed tool, a survey was administered to 272 university students. The sample size was based on Yang's rationale [14] that at least 100 cases are required to conduct a factor analysis. The inclusion criteria were as follows: university students without any cognitive impairments, communication problems, and psychiatric problems. Moreover, it was essential that students who fulfill the inclusion criteria understand the purpose of the study and provide written informed consent to participate in this study. The exclusion criterion was as follows: university students who do not agree to participate in the study.

\section{Study procedure}

\section{Tool development}

\section{Step 1: Identification of the dimensions of $\mathrm{HL}$}

A review of literature that was retrieved from scientific databases was conducted to identify factors that affect the HL of adults. We interviewed five medical professionals (i.e., 3 doctors, 1 nurse, 1 public-health educator), 30 terminally ill patients, and 50 healthy adults regarding the factors that they considered to be important in maintaining a healthy lifestyle.

\section{Step 2: Item pool generation}

An initial pool of 36 items was generated based on content that was identified by means of literature reviews and interviews. These items were classified into 12 categories, namely, sunlight, water, air, rest, exercise, meal, temperance, family history, physical condition, love, stress, and emotion.

An easy-to-use dichotomous scale (i.e., yes-no; yes $=2$, no=1) was employed to record the participant responses to each of the 36 items. The initial questionnaire was developed in the Korean language, and the first pilot study was conducted on 159 Korean adults to determine if respondents could accurately understand the meaning of the items.

\section{Step 3: Determination of the measurement scale}

In the first pilot study, participant responses were recorded on a 4-point Likert rating scale, which is more likely to produce predictable and controllable results than a dichotomous scale. The scores that were assigned to each response anchor of the Likert rating scale were as follows: $4=$ strongly agree, $3=$ agree, $2=$ disagree, and $1=$ strongly disagree.

\section{Step 4: Expert review of the initial item pool}

In order to examine content validity, 5 professors who were experts in tool development, reviewed the initial pool of 36 items. The validity of each item was assessed and a 


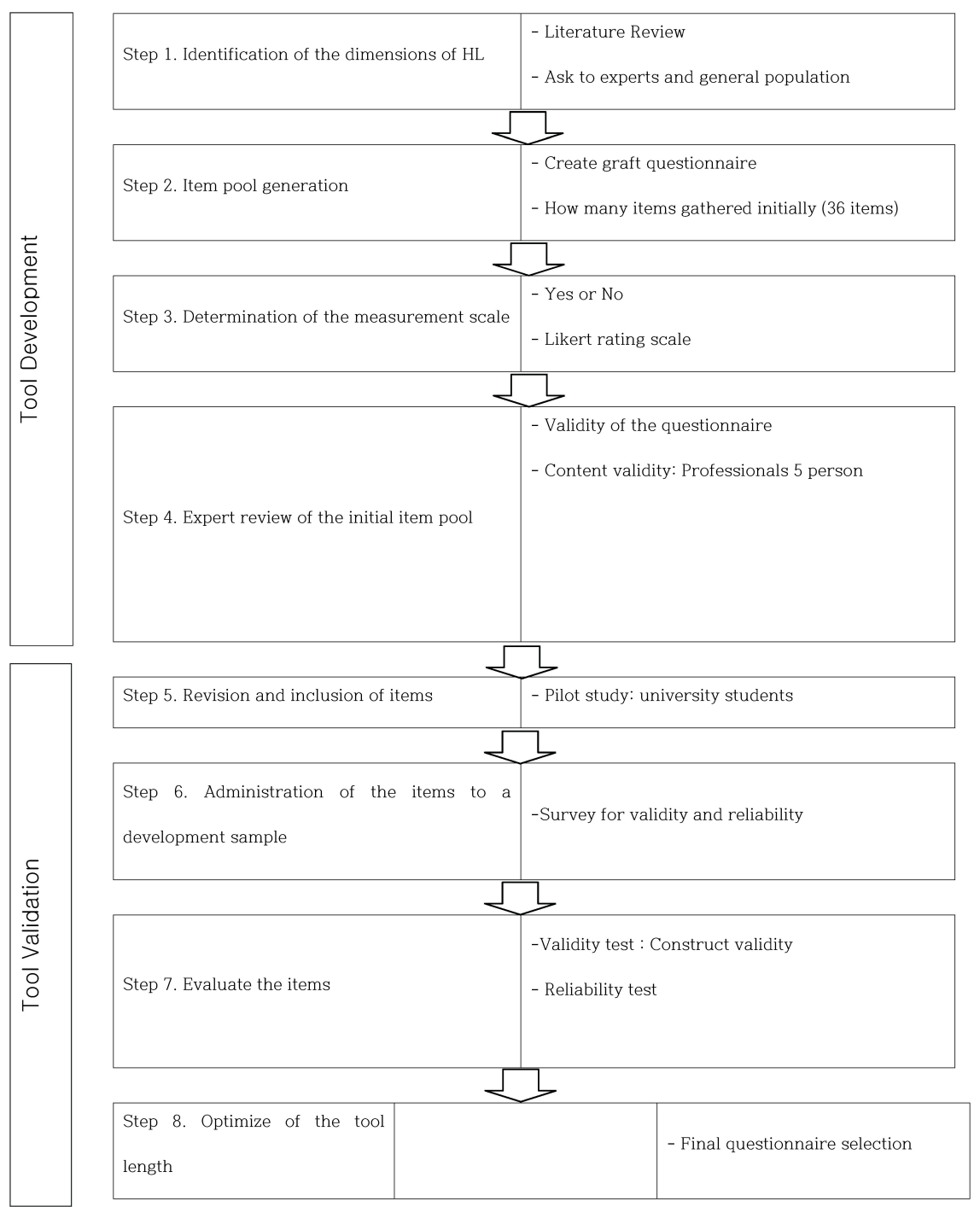

Figure 1. Tool Development Process*

*DeVellis RF. Scale development: Theory and applications: Sage publications; 2016.
Figure 1. Tool development process. Cited from the DeVellis. Scale development: Theory and applications: Sage publications; 2016 [13]. content validity index was computed [15]. Items with less than $80 \%$ "agreement" ratings between the five experts were reviewed and revised. Further, the revised items were rearranged by assigning them to appropriate categories. Accordingly, the 12 categories of the HLST (i.e., 3 items per category) were reclassified into 9 categories (i.e., 4 items per category).

\section{Step 5: Revision and inclusion of items}

After establishing the content validity of the item pool, the revised tool was translated into English for international use. The first author of this paper is Korean-American who translated the tool into English. He participated in all of the tool development processes as well as the selection process of the questions. Subsequently, the translated English questions were reviewed by English-speaking Americans. The second pilot study was conducted to determine the time that is required to respond to the questionnaire and examine the placement, composition, and comprehensibility of the items. To this end, we administered the HLST to 24 university students from a city in the Philippines. Mean and standard deviation values, and item analyses were used to test the normality of the data. 


\section{Tool validation}

\section{Step 6: Administration of the items to a development sample}

The final instrument consisted of 36 items that were selected through literature review, content validation by experts, and two pilot studies. The Korean and English versions of the HLST were developed simultaneously in order to prevent any bias related to nationality and race.

\section{Step 7: Evaluation of the items}

The validity and reliability of the questionnaire were tested by administering the final pool of 36 items to 272 college students who attended a Sahmyook University in Seoul, Korea. Data were collected using the Google's online survey platform. The online survey Uniform Resource Locator was shared only with those who agreed to participate in the research study by means of informed consent.

Following the completion of the survey, participants were compensated with drink coupons. Data was collected from June 5, 2018 to June 17, 2018; and there were no missing responses in any of the questionnaires.

\section{Step 8: Optimization of the tool length}

The final instrument, which consisted of items that the tool development procedure yielded according to the DeVellis' guidelines [13], was tested for validity and reliability.

\section{Ethical considerations}

Ethical approval for this study was granted by Sahmyook University Institutional Review Board (IRB no. 2018031HR).

\section{Data analyses}

All statistical analyses were conducted using the IBM SPSS Statistics ver. 22.0 software (IBM Co., Armonk, NY, USA).

Sample characteristics were examined using descriptive statistics (i.e., percentage, frequency, mean, standard deviation).

1. The validity of the HLST were conducted with content validity by an expert reviewer, mean inter-item correlation (MIIC), and a factor analysis using VarimaxRrotation to determine the dimensionality of the HLST [16]. Content validity involves a process of evidence building and an adequate conceptualization of the construct [17]. Whereas the MIIC is a straightforward indicator of internal consistency, the number of items is not meaningfully related to the internal consistency of a construct. MICC $>0.25$ was considered as being a sufficient level of internal consistency or reliability $[18,19]$.

2. The reliability of the total scale as well as each dimension that it subsumes were examined using Cronbach's alpha. Cronbach's alpha is the most widely used index relating to scale reliability for multi-item reflective scales in the health and social sciences [17].

\section{Results}

\section{Step 2: Generation of an item pool}

The first pilot study was conducted with a sample of 159 Korean adults. Out of the 159 subjects, 61 (38.4\%) were male and 98 (61.6\%) were female. The mean age of the sample was 58 years $( \pm 10.05)$; the age of the sample ranged from 30 to 81 years. Results of the item analysis of the initial pool of 36 items are presented in Table 1.

There were 10 items (i.e., items 5, 15, and 20-27) with item-sum correlation coefficients that were less than 0.20 . These 10 items were found to be double-barreled questions (i.e., items that simultaneously tap on two different issues); therefore, the content of each of these items was revised to ensure that it assesses only one aspect of the dimension that it measures.

\section{Step 4: Expert review of the initial Item pool}

\section{Validity: identification of the content validity by experts}

On the basis of expert feedback, a few modifications were made to the initial version of the HLST to establish its content validity. Table 2 shows the modified items that were corrected in accordance with the process of content validation.

\section{Step 5: Revision of items with low item-sum correlations}

The second pilot study was conducted with 24 university students. There were 8 items (i.e., items 3, 7, 11-12, 25-26, and 35-36) with item-sum correlation coefficients that were less than 0.20 . In total, 10 items, which included the aforementioned 8 items, were revised (Table 2).

\section{Step 7: Evaluation of the items}

The demographic details of those who had participated in the final survey $(n=272)$ are as follows: 89 students $(32.7 \%)$ were in the first grade, 58 students $(21.3 \%)$ were in the second grade, 59 students $(21.7 \%)$ were in the third grade, 54 students $(19.9 \%)$ were in the fourth grade, and 12 students 
Table 1. Internal consistency of 1 st pilot study

$(\mathrm{N}=159)$

\begin{tabular}{|c|c|c|c|c|}
\hline \multirow{2}{*}{ Category } & \multicolumn{4}{|c|}{ 1st pilot study (dichotomous scale: no 1, yes 2) } \\
\hline & Items & Mean (SD) & $\begin{array}{l}\text { Corrected item- } \\
\text { total correlation }\end{array}$ & $\begin{array}{l}\text { Alpha if } \\
\text { item deleted }\end{array}$ \\
\hline \multirow[t]{3}{*}{ Sunlight } & I go outside for $30 \mathrm{~min}$ in the sunny day & $1.55(0.49)$ & 0.364 & 0.780 \\
\hline & I like sunshine and enjoy sunbathing. & $1.57(0.49)$ & 0.357 & 0.781 \\
\hline & I use sunlight for my health promotion and care. & $1.44(0.49)$ & 0.247 & 0.785 \\
\hline \multirow[t]{3}{*}{ Water } & I drink 8 glasses of water a day. & $1.60(0.49)$ & 0.309 & 0.783 \\
\hline & I do not feel thirsty normally. & $1.67(0.47)$ & 0.259 & 0.785 \\
\hline & I choose water without mineral. & $1.51(0.50)$ & 0.130 & 0.790 \\
\hline \multirow[t]{3}{*}{ Air } & I do deep breathing in a good posture everyday. & $1.35(0.47)$ & 0.320 & 0.782 \\
\hline & I live in an area with no pollution and clean area. & $1.43(0.49)$ & 0.249 & 0.785 \\
\hline & I do deep breathing with stomach movement. & $1.22(0.41)$ & 0.254 & 0.785 \\
\hline \multirow[t]{3}{*}{ Rest } & I sleep for 7 to 8 h every day. & $1.52(0.50)$ & 0.226 & 0.786 \\
\hline & I go to bed early and wake up early. & $1.42(0.49)$ & 0.345 & 0.781 \\
\hline & I did not have sleeping issues last 6 mo. & $1.53(0.50)$ & 0.282 & 0.784 \\
\hline \multirow[t]{3}{*}{ Exercise } & I exercise for $30 \mathrm{~min}$ or more every day. & $1.53(0.50)$ & 0.365 & 0.780 \\
\hline & I do not overwork or over-exercise. & $1.62(0.48)$ & 0.315 & 0.782 \\
\hline & I do not have weight changes and I am not obese. & $1.68(0.46)$ & 0.192 & 0.787 \\
\hline \multirow[t]{3}{*}{ Diet } & I eat a vegetarian diet with lots of fibers. & $1.61(0.48)$ & 0.433 & 0.777 \\
\hline & My breakfast is the best meal of the day. & $1.58(0.49)$ & 0.230 & 0.786 \\
\hline & I do not binge eating and eat meals regularly. & $1.49(0.50)$ & 0.381 & 0.780 \\
\hline \multirow[t]{3}{*}{ Temperance } & I do not overeat or eat fast. & $1.54(0.50)$ & 0.316 & 0.782 \\
\hline & I do not drink alcohol or smoke. & $1.81(0.39)$ & 0.086 & 0.790 \\
\hline & I do not use coffee or drugs. & $1.59(0.49)$ & 0.188 & 0.787 \\
\hline \multirow[t]{3}{*}{ Family History } & My family and I do not have cancer, diabetes, or high blood pressure. & $1.17(0.37)$ & 0.131 & 0.789 \\
\hline & My family and I rarely catch a cold or flu. & $1.62(0.48)$ & 0.172 & 0.788 \\
\hline & My family and I do not use medication and maintain health. & $1.54(0.50)$ & 0.191 & 0.787 \\
\hline \multirow[t]{3}{*}{$\begin{array}{l}\text { Physical } \\
\text { Condition }\end{array}$} & $\begin{array}{l}\text { My blood pressure and blood sugar are in the normal range } \\
\text { (blood pressure 140/90, blood sugar below 140). }\end{array}$ & $1.72(0.44)$ & 0.068 & 0.792 \\
\hline & My hand and feet are always warm & $1.45(0.49)$ & -0.043 & 0.797 \\
\hline & I bowel movements at least once a day. & $1.82(0.38)$ & 0.183 & 0.787 \\
\hline \multirow[t]{3}{*}{ Love } & I am living with true love. & $1.63(0.48)$ & 0.229 & 0.786 \\
\hline & I'm not afraid of death and I am hopeful about the future. & $1.70(0.46)$ & 0.477 & 0.776 \\
\hline & I forgive others easily. & $1.64(0.48)$ & 0.311 & 0.783 \\
\hline \multirow[t]{3}{*}{ Stress } & I usually overcome stress well. & $1.58(0.49)$ & 0.359 & 0.781 \\
\hline & I always have peace and stability in my mind. & $1.55(0.49)$ & 0.357 & 0.781 \\
\hline & When in a crisis, I do not panic and solve it well. & $1.69(0.46)$ & 0.388 & 0.780 \\
\hline \multirow[t]{3}{*}{ Emotion } & I am optimistic and positive for everything & $1.60(0.49)$ & 0.297 & 0.783 \\
\hline & I do not get angry and generous to everything & $1.48(0.50)$ & 0.357 & 0.781 \\
\hline & I am happy at home and work & $1.62(0.48)$ & 0.418 & 0.778 \\
\hline
\end{tabular}

$(4.4 \%)$ were in the fifth grade. With the exception of 1 individual, all participants were unmarried.

\section{Validity: examination of internal consistency using item analysis}

Item analysis of the final pool of the HLST (Table 2) items showed that each item's mean value was neither too high nor too low. All the HLST items were subjected to further analysis the skewness $(-1.25$ to 1.26$)$ and kurtosis $(-0.01$ to
1.65) did not exceed a standard deviation (SD) of \pm 2 .

According to Briggs and Cheek's guidelines [20], the MIIC should not be less than 0.15 ; therefore, emergent MIIC values, which were either equal to or greater than 0.25 , were acceptable.

There were 8 items (i.e., items 2, 6-8, 12, 20, 25, and 28) that were tested for inter-sum correlations. Additionally, four items (i.e., items 6-7, 12, and 28) were newly added to the existing pool of items. Across all 8 items, the degree of 
Table 2. Results of internal consistency and Cronbach's alpha

$(\mathrm{N}=296)$

\begin{tabular}{|c|c|c|c|c|c|c|c|c|c|c|}
\hline \multirow[b]{2}{*}{ Category } & \multicolumn{4}{|c|}{ The 2nd pilot study $(n=24)$} & \multicolumn{6}{|c|}{ The final study $(\mathrm{n}=272)$} \\
\hline & Items & Mean (SD) & $\begin{array}{l}\text { The } \\
\text { MIIC }\end{array}$ & $\begin{array}{l}\text { Alpha } \\
\text { if item } \\
\text { deleted }\end{array}$ & Items & Mean (SD) & Skewness & Kurtosis & $\begin{array}{l}\text { The } \\
\text { MIIC }\end{array}$ & $\begin{array}{l}\text { Alpha } \\
\text { if item } \\
\text { deleted }\end{array}$ \\
\hline \multirow[t]{4}{*}{ Sunlight } & 1. I go outside for $10 \mathrm{~min}$ in the sun. & $3.50(0.72)$ & 0.306 & 0.790 & $\begin{array}{l}\text { 1. I go outside for the sun at least } \\
10 \text { min a day. }\end{array}$ & $3.18(0.68)$ & -0.390 & -0.299 & 0.259 & 0.698 \\
\hline & $\begin{array}{l}\text { 2. I use a sun protection (hat, } \\
\text { sunscreen) every time I go out. }\end{array}$ & $2.45(1.02)$ & 0.251 & 0.793 & $\begin{array}{l}\text { 2. I use a sun protection } \\
\text { (sunscreen) properly. }\end{array}$ & $2.90(1.02)$ & -0.446 & -0.980 & 0.107 & 0.709 \\
\hline & $\begin{array}{l}\text { 3. When sleeping at night, there is no } \\
\text { light and it is quiet. }\end{array}$ & $3.25(1.03)$ & 0.165 & 0.797 & $\begin{array}{l}\text { 3. I expose skin properly when I } \\
\text { go out for sunlight. }\end{array}$ & $2.81(0.74)$ & -0.287 & -0.085 & 0.209 & 0.701 \\
\hline & $\begin{array}{l}\text { 4. I work in an office with no natural } \\
\text { light. }\end{array}$ & $2.95(0.90)$ & 0.311 & 0.790 & $\begin{array}{l}\text { 4. I work (study) in a place where } \\
\text { the amount of sunlight is good. }\end{array}$ & $2.05(0.75)$ & 0.354 & -0.125 & 0.277 & 0.697 \\
\hline \multirow[t]{4}{*}{ Water } & 5. I drink 8 glasses of water a day. & $3.20(0.72)$ & 0.422 & 0.786 & $\begin{array}{l}\text { 5. I drink and glasses of water } \\
\text { daily. }\end{array}$ & $2.48(0.94)$ & 0.118 & -0.873 & 0.244 & 0.698 \\
\hline & $\begin{array}{l}\text { 6. I drink other sweet beverages } \\
\text { (sugar) besides water. }\end{array}$ & $3.91(0.28)$ & 0.218 & 0.794 & 6. I often feel thirsty. & $2.38(0.70)$ & -0.031 & -0.267 & 0.070 & 0.708 \\
\hline & 7. I do not feel thirsty normally. & $1.08(0.28)$ & 0.166 & 0.799 & 7. I drink water during the meals. & $2.26(0.96)$ & 0.285 & -0.879 & 0.038 & 0.713 \\
\hline & $\begin{array}{l}\text { 8. I take caffeinated drinks (coffee, } \\
\text { tea, and energy drinks). }\end{array}$ & $2.58(1.01)$ & 0.233 & 0.815 & $\begin{array}{l}\text { 8. I drink caffeinated drinks (coffee, } \\
\text { tea, supplements, energy drinks, } \\
\text { etc.). }\end{array}$ & $2.29(0.97)$ & 0.229 & -0.936 & 0.055 & 0.712 \\
\hline \multirow[t]{4}{*}{ Air } & $\begin{array}{l}\text { 9. I do deep breathing throughout the } \\
\text { day }\end{array}$ & $2.12(0.74)$ & 0.294 & 0.791 & $\begin{array}{l}\text { 9. I do deep breathing throughout } \\
\text { the day. }\end{array}$ & $2.66(0.76)$ & -0.020 & -0.389 & 0.222 & 0.700 \\
\hline & $\begin{array}{l}\text { 10. I breathe through my mouth } \\
\text { when hiking or exercising. }\end{array}$ & $2.66(1.20)$ & 0.483 & 0.781 & $\begin{array}{l}\text { 10. I live in an area with clean air } \\
\text { quality. }\end{array}$ & $2.38(0.85)$ & 0.047 & -0.615 & 0.194 & 0.702 \\
\hline & $\begin{array}{l}\text { 11. I live in an area with an } \\
\text { unhealthy level of polluted air. }\end{array}$ & $2.12(0.85)$ & 0.131 & 0.807 & 11. I keep indoor air quality clean. & $2.61(0.71)$ & -0.022 & -0.247 & 0.402 & 0.690 \\
\hline & $\begin{array}{l}\text { 12. I smoke or exposed to } \\
\text { second-hand smoking. }\end{array}$ & $3.29(0.85)$ & 0.188 & 0.795 & $\begin{array}{l}\text { 12. I breathe through my mouth } \\
\text { when hiking or exercising }\end{array}$ & $2.69(0.72)$ & -0.376 & 0.076 & 0.043 & 0.714 \\
\hline \multirow[t]{4}{*}{ Rest } & 13. I sleep for 7 to $8 \mathrm{~h}$ every day. & $2.75(0.67)$ & 0.291 & 0.791 & 13. I sleep for 7 to $8 \mathrm{~h}$. & $2.38(0.84)$ & 0.062 & -0.593 & 0.196 & 0.702 \\
\hline & $\begin{array}{l}\text { 14. I use electronic devices for more } \\
\text { than } 3 \mathrm{~h} \text { in the evening. }\end{array}$ & $2.08(1.01)$ & 0.630 & 0.774 & $\begin{array}{l}\text { 14. I use electronic devices (TV, } \\
\text { computer, or phone) for more } \\
\text { than } 3 \mathrm{~h} \text { in the evening. }\end{array}$ & $1.70(0.70)$ & 0.690 & 0.027 & 0.224 & 0.700 \\
\hline & $\begin{array}{l}\text { 15. I keep a balance between } \\
\text { work/studies and rest. }\end{array}$ & $2.70(0.85)$ & 0.568 & 0.779 & $\begin{array}{l}\text { 15. I do not exercise right before } \\
\text { bedtime }\end{array}$ & $1.68(0.75)$ & 0.981 & 0.690 & 0.150 & 0.704 \\
\hline & $\begin{array}{l}\text { 16. I go to bed early and do not stay } \\
\text { up late. }\end{array}$ & $2.66(0.76)$ & 0.551 & 0.781 & $\begin{array}{l}\text { 16. I go to bed early and wake up } \\
\text { early. }\end{array}$ & $2.02(0.88)$ & 0.462 & -0.615 & 0.282 & 0.696 \\
\hline \multirow[t]{4}{*}{ Exercise } & $\begin{array}{l}\text { 17. I exercise for } 30 \mathrm{~min} \text { or more } \\
\text { every day. }\end{array}$ & $1.95(0.90)$ & 0.522 & 0.781 & $\begin{array}{l}\text { 17. I exercise for more than } 30 \\
\text { min every day. }\end{array}$ & $2.06(0.86)$ & 0.536 & -0.272 & 0.348 & 0.692 \\
\hline & 18. I usually sweat when I exercise & $2.62(0.87)$ & 0.270 & 0.792 & $\begin{array}{l}\text { 18. I usually sweat when I } \\
\text { exercise. }\end{array}$ & $2.91(0.89)$ & -0.428 & -0.567 & 0.221 & 0.700 \\
\hline & $\begin{array}{l}\text { 19. I do enjoy physical activity } \\
\text { whenever I have time }\end{array}$ & $2.79(0.72)$ & 0.364 & 0.788 & $\begin{array}{l}\text { 19. I enjoy physical activity } \\
\text { whenever I have time. }\end{array}$ & $2.54(0.85)$ & -0.145 & -0.592 & 0.435 & 0.740 \\
\hline & $\begin{array}{l}\text { 20. When I work, I stay in one } \\
\text { position for long period time. }\end{array}$ & $2.20(0.50)$ & 0.344 & 0.790 & $\begin{array}{l}\text { 20. When I work, I stay in one } \\
\text { position for long period time. }\end{array}$ & $2.63(0.79)$ & -0.077 & -0.412 & 0.089 & 0.708 \\
\hline \multirow[t]{4}{*}{ Nutrition } & 21. I eat a healthy breakfast regularly. & $2.70(0.95)$ & 0.386 & 0.787 & $\begin{array}{l}\text { 21. My breakfast is the best meal } \\
\text { of the day }\end{array}$ & $1.72(0.86)$ & 1.055 & 0.384 & 0.259 & 0.698 \\
\hline & $\begin{array}{l}\text { 22. I enjoy eating snacks between } \\
\text { meals }\end{array}$ & $3.29(0.80)$ & 0.232 & 0.793 & 22. I eat meals regularly. & $2.34(0.85)$ & 0.202 & -0.547 & 0.474 & 0.683 \\
\hline & $\begin{array}{l}\text { 23. I eat food slowly and chew } \\
\text { it well }\end{array}$ & $2.95(0.85)$ & 0.339 & 0.789 & $\begin{array}{l}\text { 23. I eat food slowly and chew it } \\
\text { well }\end{array}$ & $2.60(0.83)$ & 0.063 & -0.598 & 0.276 & 0.697 \\
\hline & 24. I eat a vegetarian diet. & $2.58(0.82)$ & 0.357 & 0.788 & $\begin{array}{l}\text { 24. I eat nutritionally balanced } \\
\text { diet. }\end{array}$ & $2.35(0.80)$ & 0.248 & -0.327 & 0.534 & 0.681 \\
\hline \multirow[t]{4}{*}{ Temperance } & 25. I do not overeat. & $3.20(0.72)$ & 0.063 & 0.798 & $\begin{array}{l}\text { 25. When I feel blue, I often } \\
\text { overeat. }\end{array}$ & $2.40(0.92)$ & 0.167 & -0.795 & 0.106 & 0.708 \\
\hline & 26. I drink alcohol. & $3.00(0.97)$ & 0.110 & 0.799 & $\begin{array}{l}\text { 26. I did not drink alcohol for last } \\
12 \mathrm{mo}\end{array}$ & $1.72(1.02)$ & 1.260 & 0.323 & 0.212 & 0.701 \\
\hline & $\begin{array}{l}\text { 27. I get angry or annoyed more } \\
\text { easily than before. }\end{array}$ & $3.04(0.75)$ & 0.488 & 0.784 & $\begin{array}{l}\text { 27. I keep a balance between } \\
\text { work (study) and rest. }\end{array}$ & $2.66(0.71)$ & -0.524 & 0.191 & 0.423 & 0.689 \\
\hline & 28. I am satisfied with my daily life. & $3.00(0.88)$ & 0.225 & 0.793 & $\begin{array}{l}\text { 28. I did not smoke within last } 6 \\
\text { mo. }\end{array}$ & $3.63(0.88)$ & -1.248 & 1.346 & 0.110 & 0.707 \\
\hline
\end{tabular}


Table 2. Continued

$(\mathrm{N}=296)$

\begin{tabular}{|c|c|c|c|c|c|c|c|c|c|c|}
\hline \multirow[b]{2}{*}{ Category } & \multicolumn{4}{|c|}{ The 2nd pilot study ( $\mathrm{n}=24)$} & \multicolumn{6}{|c|}{ The final study $(\mathrm{n}=272)$} \\
\hline & Items & Mean (SD) & $\begin{array}{l}\text { The } \\
\text { MIIC }\end{array}$ & $\begin{array}{l}\text { Alpha } \\
\text { if item } \\
\text { deleted }\end{array}$ & Items & Mean (SD) & Skewness & Kurtosis & $\begin{array}{l}\text { The } \\
\text { MIIC }\end{array}$ & $\begin{array}{l}\text { Alpha } \\
\text { if item } \\
\text { deleted }\end{array}$ \\
\hline \multirow[t]{4}{*}{ Trust } & 29. I can trust most people. & $3.00(0.65)$ & 0.215 & 0.793 & 29. I have a purpose of life. & $3.02(0.73)$ & -0.495 & 0.234 & 0.353 & 0.693 \\
\hline & $\begin{array}{l}\text { 30. I'm not afraid of death and I am } \\
\text { hopeful about the future. }\end{array}$ & $3.37(0.64)$ & 0.517 & 0.784 & 30. I am hopeful about the future. & $3.09(0.72)$ & -0.441 & -0.010 & 0.435 & 0.689 \\
\hline & $\begin{array}{l}\text { 31. I feel loved by my family and } \\
\text { friends. }\end{array}$ & $3.37(0.64)$ & 0.454 & 0.786 & $\begin{array}{l}\text { 31. I feel loved by my family and } \\
\text { friends. }\end{array}$ & $3.32(0.66)$ & -0.606 & 0.025 & 0.387 & 0.692 \\
\hline & $\begin{array}{l}\text { 32. I pray or meditate on a regular } \\
\text { basis. }\end{array}$ & $3.29(0.62)$ & 0.449 & 0.786 & $\begin{array}{l}\text { 32. I pray or meditate on a regular } \\
\text { basis. }\end{array}$ & $1.98(0.86)$ & 0.490 & -0.543 & 0.298 & 0.695 \\
\hline \multirow{4}{*}{$\begin{array}{l}\text { General } \\
\text { physical } \\
\text { condition }\end{array}$} & $\begin{array}{l}\text { 33. There has been little change in } \\
\text { my weight over the past year. }\end{array}$ & $3.08(0.82)$ & 0.265 & 0.792 & $\begin{array}{l}\text { 33. I maintain my weight } \\
\text { properly. }\end{array}$ & $2.82(0.81)$ & -0.340 & -0.305 & 0.302 & 0.695 \\
\hline & $\begin{array}{l}\text { 34. I did not catch a cold or flu for } \\
\text { one year. }\end{array}$ & $1.91(0.97)$ & 0.289 & 0.791 & $\begin{array}{l}\text { 34. My blood pressure is in the } \\
\text { normal range. }\end{array}$ & $3.24(0.68)$ & -0.769 & 1.020 & 0.154 & 0.704 \\
\hline & $\begin{array}{l}\text { 35. My blood pressure and blood } \\
\text { sugar are in the normal range. }\end{array}$ & $3.50(0.51)$ & 0.117 & 0.796 & $\begin{array}{l}\text { 35. My blood sugar is in the } \\
\text { normal range. }\end{array}$ & $3.25(0.57)$ & -0.305 & 0.810 & 0.261 & 0.699 \\
\hline & $\begin{array}{l}\text { 36. I have bowel movements at least } \\
\text { once a day. }\end{array}$ & $3.37(0.87)$ & 0.055 & 0.800 & $\begin{array}{l}\text { 36. I have regular bowel } \\
\text { movements. }\end{array}$ & $2.99(0.79)$ & -0.526 & -0.043 & 0.212 & 0.701 \\
\hline
\end{tabular}

skewness and kurtosis did not exceed a $\mathrm{SD}$ of \pm 2 .

\section{Validity: identification of the hypothesized factors us- ing factor analysis}

\section{- The appropriateness for factor analysis}

The Kaiser-Meyer-Olkin (KMO) test was conducted to determine the appropriateness of the HLST and yielded a value of 0.81 . In other words, given that the KMO value was equal to or above 0.80 , it was appropriate to factor analyze the data [21]. In addition, according to the results of Bartlett's test [22] of sphericity, the $\chi^{2}$ value was 2,128.49 $(p<0.00)$; therefore, the items were found to be appropriate for factor analysis.

\section{- Factor extraction and rotation}

Varimax rotation was conducted with specifications that the 9 factors were to be extracted. The eigenvalue of all the 9 factors were above 1.00; these nine factors together accounted for $50.4 \%$ of the total variance.

The first factor evidenced acceptable loadings from 7 items (range, $0.35-0.75$ ) and accounted for $13.3 \%$ of the variance; the eigenvalue of this factor was 4.78 . The second factor evidenced acceptable loadings from 4 items (range, 0.380.77 ) and accounted for $7.2 \%$ of the variance; the eigenvalue of this factor was 2.58 . The third factor evidenced acceptable loadings from 5 items (range, 0.34-0.76) and accounted for $5.7 \%$ of the variance; the eigenvalue of this factor was
2.05 .

The fourth factor evidenced acceptable loadings from 4 items (range, $0.34-0.73$ ) and explained $5.2 \%$ of the variance; the eigenvalue of this factor was 1.86 . The fifth factor evidenced acceptable loadings from 3 items (range, 0.32-0.78) and explained $4.22 \%$ of the variance; the eigenvalue of this factor was 1.52. The sixth factor evidenced acceptable loadings from 4 items (range, 0.35-0.66) and accounted for 4.1\% of the variance; the eigenvalue of this factor was 1.48 . The seventh factor evidenced acceptable loadings from 3 items (range, $0.37-0.60$ ) and accounted for $3.9 \%$ of the variance; the eigenvalue of this factor was 1.39 . The eighth factor evidenced acceptable loadings from 4 items (range, 0.40-0.56) and accounted for $3.5 \%$ of the variance; the eigenvalue of this factor 1.27 . The ninth factor evidenced acceptable loadings from 2 items (range, 0.48-0.79) and accounted for 3.3\% of the variance; the eigenvalue of this factor was 1.20 (Table 3 ).

\section{Reliability: examination of internal consistency using Cronbach's alpha}

The reliability of the HLST was determined using Cronbach's alpha and was found to be acceptable $(\alpha=0.71)$.

\section{Step 8. Optimization of scale length}

The HLST, which screens the HL among young adults, consists of 36 items that measure 9 factors (i.e., 4 items per factor). The 9 factors, each of which consist of 4 items, are as follows: sunlight (items 1 to 4 ), water (items 5 to 8 ), air 
Table 3. Result of factor analysis on the Healthy Lifestyle Screening Tool

\begin{tabular}{|c|c|c|c|c|c|c|c|c|c|}
\hline \multirow{2}{*}{ No } & \multicolumn{9}{|c|}{ Factor } \\
\hline & 1 & 2 & 3 & 4 & 5 & 6 & 7 & 8 & 9 \\
\hline 19 & -0.745 & -0.167 & -0.034 & -0.017 & -0.013 & -0.091 & -0.046 & 0.068 & -0.144 \\
\hline 17 & 0.738 & 0.131 & 0.175 & -0.150 & 0.072 & -0.083 & 0.065 & -0.119 & 0.080 \\
\hline 18 & 0.565 & 0.071 & 0.037 & 0.088 & 0.094 & -0.039 & -0.108 & 0.075 & -0.073 \\
\hline 5 & 0.466 & -0.060 & 0.181 & 0.222 & -0.079 & 0.105 & 0.032 & 0.175 & 0.060 \\
\hline 15 & 0.405 & 0.050 & 0.128 & -0.265 & -0.151 & 0.272 & 0.317 & -0.213 & -0.241 \\
\hline 1 & 0.390 & 0.312 & 0.046 & 0.219 & -0.264 & -0.035 & -0.071 & 0.200 & 0.081 \\
\hline 3 & 0.349 & 0.115 & -0.025 & 0.318 & 0.217 & -0.257 & -0.089 & 0.209 & 0.064 \\
\hline 30 & 0.135 & 0.770 & 0.056 & 0.132 & 0.069 & 0.118 & -0.079 & -0.033 & 0.038 \\
\hline 29 & 0.066 & 0.726 & 0.019 & 0.122 & 0.074 & 0.104 & -0.087 & -0.028 & -0.065 \\
\hline 31 & 0.143 & 0.643 & 0.080 & 0.190 & 0.057 & 0.039 & 0.017 & 0.164 & -0.032 \\
\hline 27 & 0.161 & 0.381 & 0.292 & 0.040 & 0.047 & 0.063 & 0.042 & -0.094 & 0.181 \\
\hline 24 & 0.203 & 0.111 & 0.756 & 0.218 & 0.087 & 0.001 & -0.076 & 0.033 & -0.016 \\
\hline 22 & 0.122 & 0.067 & 0.753 & 0.094 & 0.047 & 0.031 & 0.075 & 0.002 & 0.066 \\
\hline 23 & -0.174 & 0.174 & 0.591 & 0.021 & -0.035 & 0.178 & -0.046 & 0.060 & -0.017 \\
\hline 21 & 0.210 & -0.119 & 0.581 & -0.239 & 0.140 & -0.022 & -0.092 & -0.109 & 0.180 \\
\hline 14 & 0.219 & 0.123 & 0.342 & -0.026 & -0.208 & 0.021 & 0.318 & 0.073 & -0.057 \\
\hline 35 & 0.072 & 0.274 & 0.015 & 0.729 & -0.150 & 0.029 & -0.020 & -0.201 & 0.079 \\
\hline 34 & 0.029 & 0.239 & -0.061 & 0.677 & -0.216 & -0.036 & 0.071 & -0.234 & 0.089 \\
\hline 36 & 0.060 & 0.094 & 0.107 & 0.613 & 0.073 & 0.096 & 0.024 & 0.148 & -0.153 \\
\hline 25 & -0.040 & -0.103 & 0.173 & 0.335 & 0.089 & -0.075 & 0.326 & -0.189 & 0.027 \\
\hline 26 & 0.067 & 0.023 & 0.091 & -0.053 & 0.775 & 0.006 & 0.061 & -0.113 & 0.021 \\
\hline 32 & 0.154 & 0.254 & -0.015 & -0.091 & 0.634 & 0.248 & -0.004 & 0.140 & 0.058 \\
\hline 28 & -0.249 & 0.297 & 0.087 & -0.082 & 0.323 & -0.198 & 0.161 & -0.192 & 0.103 \\
\hline 10 & -0.044 & 0.226 & 0.099 & -0.093 & 0.114 & 0.663 & -0.008 & -0.039 & -0.065 \\
\hline 11 & 0.234 & 0.194 & 0.120 & 0.256 & 0.007 & 0.603 & 0.023 & 0.256 & 0.159 \\
\hline 8 & -0.160 & -0.221 & 0.013 & 0.182 & 0.268 & 0.419 & 0.276 & -0.063 & 0.272 \\
\hline 20 & -0.034 & 0.064 & 0.178 & 0.080 & 0.299 & -0.350 & 0.089 & 0.200 & -0.260 \\
\hline 7 & 0.029 & -0.081 & 0.036 & -0.078 & 0.070 & 0.010 & 0.601 & -0.035 & -0.060 \\
\hline 12 & 0.026 & 0.013 & 0.107 & -0.162 & -0.035 & -0.029 & -0.579 & -0.043 & -0.011 \\
\hline 9 & 0.346 & 0.056 & 0.122 & 0.109 & 0.180 & 0.307 & -0.368 & -0.049 & -0.198 \\
\hline 2 & -0.117 & 0.351 & 0.070 & -0.143 & -0.055 & -0.076 & 0.320 & 0.561 & -0.001 \\
\hline 6 & -0.089 & 0.169 & 0.032 & 0.036 & 0.096 & 0.039 & 0.348 & -0.490 & -0.192 \\
\hline 33 & 0.042 & 0.352 & 0.179 & 0.103 & 0.094 & -0.016 & -0.007 & -0.428 & 0.303 \\
\hline 4 & 0.315 & 0.107 & 0.197 & -0.121 & 0.197 & 0.130 & -0.049 & 0.396 & 0.036 \\
\hline 13 & 0.051 & 0.069 & 0.111 & 0.028 & 0.050 & 0.112 & -0.101 & 0.057 & 0.791 \\
\hline 16 & 0.255 & -0.043 & 0.465 & -0.150 & 0.008 & -0.240 & 0.162 & 0.047 & 0.479 \\
\hline \multicolumn{2}{|c|}{ Factor } & \multicolumn{2}{|c|}{ Eigenvalue } & \multicolumn{3}{|c|}{ Variance explained (\%) } & \multicolumn{3}{|c|}{ Cumulative variance explained (\%) } \\
\hline \multicolumn{2}{|c|}{1} & \multicolumn{2}{|r|}{4.783} & \multicolumn{3}{|c|}{13.286} & \multicolumn{3}{|c|}{13.286} \\
\hline \multicolumn{2}{|c|}{2} & \multicolumn{2}{|r|}{2.577} & \multicolumn{3}{|c|}{7.159} & \multicolumn{3}{|c|}{20.445} \\
\hline \multicolumn{2}{|c|}{3} & \multicolumn{2}{|r|}{2.053} & \multicolumn{3}{|c|}{5.702} & \multicolumn{3}{|c|}{26.147} \\
\hline \multicolumn{2}{|c|}{4} & \multicolumn{2}{|r|}{1.863} & & 5.17 & & & 31.321 & \\
\hline & & & 1.520 & & 4.22 & & & 35.544 & \\
\hline & & & 1.478 & & 4.10 & & & 39.651 & \\
\hline & & & 1.393 & & 3.87 & & & 43.520 & \\
\hline & & & 1.273 & & 3.53 & & & 47.055 & \\
\hline & & & 1.197 & & 3.32 & & & 50.379 & \\
\hline
\end{tabular}


(items 9 to 12), rest (items 13 to 16), exercise (items 17 to 20), nutrition (items 21 to 24), temperance (items 25 to 28), trust (items 29 to 32), and general physical condition (items 33 to 36). Scores are computed using responses recorded on the following 4-point Likert rating scale: $4=$ strongly agree, 3 =agree, $2=$ disagree, and $1=$ strongly disagree.

Scores on the HLST can range from 36 to 144; moreover, factor-wise scores can each range from 4 to 16 . High scores on the HLST are indicative of a HL; high factor-specific scores are indicative of higher adherence to the respective dimension of a HL (Appendix).

\section{Discussion}

The HLST measures 9 independent dimensions of a HL but it does not measure psychosocial characteristics. The discussion regarding the validity of the HLST was described based on the content validity and the MIIC.

\section{Validity}

\section{Sunlight}

The 4 items that are subsumed by this factor assess appropriate skin exposure to sunlight (i.e., approximately $10 \mathrm{mi}$ nutes per day). Items that belong to this dimension pertain to the positive effects (i.e., a rich source of vitamin D for the body, prevention of autoimmune diseases, reduction of melanoma risk, improved immunologic tolerance, and endorphin-related effects) of skin exposure to moderate amounts of sunlight, as well as its negative effects (i.e., cataracts) $[23,24]$. Item analysis showed that 3 items had MIIC values that were 0.20 or greater. The item, "I use sun protection (sunscreen) properly," evidenced a value of 0.11 . However, this item was retained because it tapped on strategies that are used to prevent the negative effects of sunburn that result from overexposure to sunlight.

\section{Water}

Sufficient daily water intake is important for the maintenance of good health; conversely, insufficient water intake has been known to cause thirst, reduce exercise performance, and adversely affect working memory and mood [25, 26]. The 4 items that belong to this factor assess water ingestion, thirst, caffeine ingestion, and water intake during meals. The MIIC of one item (i.e., "I drink 8 glasses of water daily") was found to be 0.24 ; however, the other 3 items evidenced low correlation coefficients (i.e., 0.10). Therefore, further refinement and validation of these three items through literature review and further research is necessary.

\section{Air}

This factor, which is comprised of 4 items, assesses deep breathing and clean atmospheric environments. Brunt et al.'s study [27] showed that air pollution is significantly and positively correlated with respiratory health. Therefore, they recommended that it is important to obtain an air quality index to assess the health status of vulnerable individuals. Further, they also asserted that air pollution-related risks should be considered as determinants of health [28]. To achieve this, greater integration of public health and policy, collaboration with local air quality management [27], and efforts to clean air and maintain a HL have been suggested. The MIIC of the 3 items ranged from 0.20 to 0.40 . One item that was related to breathing exercises evidenced a low correlation coefficient (i.e., 0.04); however, this item was not deleted because its effect on the reliability of total items was low.

\section{Rest}

The 4 items that belong to this factor assess the presence of sufficient hours of sleep and the habit of going to sleep early. Given that lifestyle has been associated with sleep habits, fatigue, and positive and negative self-efficacy, it has been emphasized that increasing individuals' sleep- and lifestyle-related self-efficacy can contribute to the promotion of positive health outcomes [29]. Further, a study of health problems among footwear factory workers found significant correlations between sleep quality, nicotine and alcohol dependence, and work-related musculoskeletal discomfort [30]. These results were the basis upon which we considered it necessary to measure sleep habits within this factor.

\section{Exercise}

Exercise has been reported as a very important factor in the maintenance of good health [31-33]. Todde et al. [33] has suggested that high-intensity exercise and functional exercises can improve functional mobility and muscle endurance among those who are above the age of 65 .

The 4 items that belong to this factor assess endurance exercises that last for over 30 minutes per day. The MIIC of 3 out of the four items ranged from 0.20 to 0.40 ; the item "that assesses the keeping same position over a long period of time" evidenced a low correlation coefficient $(\mathrm{r}<0.10)$. Wisse et al. [34] has suggested that people must be encouraged to change their sedentary lifestyles; this is especially 
necessary for those who require long-term physical therapy.

\section{Nutrition}

The 4 items of this factor assess individual intake of regular and balanced meals. The MIIC of the 4 items evidenced correlation coefficients that ranged from 0.25 to .53 or more. Fleig et al.'s findings [35] suggest that habit strength and transfer cognitions are important factors that underlie the relationship between exercise and nutrition. Moreover, an optimal level of nutrition and healthy lifestyle play a vital role in healing and maintaining a healthy thyroid function [36]. Indeed, recent studies have presented regular and balanced meals as effective guidelines for nutrition maintenance.

\section{Temperance}

Self-control is related to several positive outcomes, such as mental health, interpersonal success, academic success, and health-related behaviors. Moreover, self-regulation has been linked to improved health outcomes and functional limitations among older Americans [37]. The temperance factor of the HLST assesses unhealthy coping strategies, control of food intake, alcohol, smoking, and work-life balance. Two items that measure smoking and overeating were found to have MIIC values that were less than 0.10. Low level of physical activity was the most common risk factor that emerged during the initial and follow-up visits. However, O'Donoghue et al. [11] have posited that physical therapists should also consider dietary status, smoking, and alcohol consumption as possible risk factors.

\section{Trust}

The 4 items that belong to this factor assess purpose in life, hope, positive social relations, and regular mind training. Social desirability response sets can bias self-reported psychological well-being in late adulthood. Moreover, lifestyle and perceived physical health are related and influence the perceived QoL of older adults [38]. Campos-Matos et al. [39] have suggested that contextual trust plays a complex role in explaining health inequalities and self-reported health. In addition, spiritual-mind-body beliefs, which may serve either as barriers or motivators to obtaining and adhering to treatment, are important factors that affect the survival and QoL of patients with advanced or terminal illnesses [40]. Consistent with past findings, the MIIC values of all the items in this factor were found to have correlation coefficients that were 0.30 or higher.

\section{General Physical condition}

The, 4 items that belong to this factor measure one's general physical condition (i.e., body weight, blood pressure, blood sugar, and bowel habits); in other words, it is an indicator of overall health status. Past studies that have been conducted across many countries have linked obesity, smoking, heavy drinking, poor diet, and a lack of physical activity to morbidity and mortality [41,42]. Indeed, weight, blood pressure, blood sugar, and bowel habits are useful indicators of overall physical health.

\section{Reliability}

The HLST, which comprises 9 factors that assess HL, was found to have an acceptable Cronbach's alpha of 0.71 ; an alpha that is between 0.70 and 0.90 is indicative of a reliability that is acceptable [43].

Patients who receive physical therapy prefer therapeutic interventions that are based on their health problems. In order to provide medical services that address unique patient needs, it is necessary to evaluate not only conventional approaches to physical therapy but also the patient's lifestyle-related limitations, when conducting physical activities or prescribing exercise routines. The tool that has been developed in this study is a holistic assessment of a HL. Thus, the HLST can serve as a useful assessment in integrated therapeutic approaches that are cognizant of the role that lifestyle behaviors play in a HL.

The validity and reliability of the final 36 items were tested on one university students. They did not represent the total population of university students across all cultural groups in Korean society. This limitation indicates that further research is required into the HLST to eliminate the effects of selection, information bias to strengthen the validity and reliability obtained thus far.

\section{Conflict of Interest}

The authors declared no potential conflicts of interest with respect to the authorship and/or publication of this article.

\section{References}

1. Reynolds SL. Successful aging in spite of bad habits: introduction to the special section on 'Life style and health expectancy'. Eur J Ageing 2008;5:275.

2. Austin-McCain M. An examination of the association of social 
media use with the satisfaction with daily routines and healthy lifestyle habits for undergraduate and graduate students. Open J Occup Ther 2017. doi: 10.15453/2168-6408.1327.

3. Cihangiroğlu Z, Deveci SE. Healthy life style behaviours and related influencing factors of the students of elazig high school of health sciences of Firat university. Firat Med J 2011;16:78-83.

4. Cambridge Dictionary. Cambridge advanced learner's dictionary $\&$ thesaurus [Internet]. Cambridge University Press, Available from: https://dictionary.cambridge.org/ko/\%EC\%82\%AC\%EC\%A0\%84/.

5. Kockanat $P$, Bekar M. The relationship between sexual health behaviors and healthy lifestyle behaviors of female students in Turkey. Int J Caring Sci 2018;11:1859-67.

6. Aslan E, Bektas H, Basgol S, Demir SV. PI Level of information and patterns of behaviour of university students in relation to sexual health. J Contin Med Educ 2014;23:174-82.

7. Addley K, McQuillan P, Ruddle M. Creating healthy workplaces in Northern Ireland: evaluation of a lifestyle and physical activity assessment programme. Occup Med (Lond) 2001;51:439-49.

8. Darviri C, Alexopoulos EC, Artemiadis AK, Tigani X, Kraniotou C, Darvyri P, et al. The Healthy Lifestyle and Personal Control Questionnaire (HLPCQ): a novel tool for assessing self-empowerment through a constellation of daily activities. BMC Public Health 2014. doi: 10.1186/1471-2458-14-995.

9. Black B, Ingman M, Janes J. Physical therapists' role in health promotion as perceived by the patient: descriptive survey. Phys Ther 2016;96:1588-96.

10. Dean E, Söderlund A. What is the role of lifestyle behaviour change associated with non-communicable disease risk in managing musculoskeletal health conditions with special reference to chronic pain? BMC Musculoskelet Disord 2015. doi: 10.1186/ s12891-015-0545-y.

11. O'Donoghue G, Cunningham C, Murphy F, Woods C, AagaardHansen J. Assessment and management of risk factors for the prevention of lifestyle-related disease: a cross-sectional survey of current activities, barriers and perceived training needs of primary care physiotherapists in the Republic of Ireland. Physiotherapy 2014;100:116-22.

12. Heckman KA, Cott CA. Home-based physiotherapy for the elderly: a different world. Physiother Can 2005;57:274-83.

13. DeVellis RF. Scale development: theory and applications. SAGE Publications; 2016.

14. Yang B. Multivariate data analysis and its applications. Seoul: Hakji Publishing Co.; 1998.

15. Lynn MR. Determination and quantification of content validity. Nurs Res 1986;35:382-5.

16. Taylor GJ, Bagby RM, Parker JD. The 20-Item Toronto Alexithymia Scale. IV. Reliability and factorial validity in different languages and cultures. J Psychosom Res 2003;55:277-83.

17. Polit DF, Yang FM. Measurement and the measurement of change: a primer for the health professions. Philadelphia (PA): Wolters Kluwer; 2016.

18. Clark LA, Watson D. Constructing validity: basic issues in objective scale development. Psychol Assess 1995;7:309-19.

19. van Leeuwen R, Tiesinga LJ, Middel B, Post D, Jochemsen H. The validity and reliability of an instrument to assess nursing competencies in spiritual care. J Clin Nurs 2009;18:2857-69.

20. Briggs SR, Cheek JM. The role of factor analysis in the development and evaluation of personality scales. J Personal 1986;54:
$106-48$.

21. Kaiser HF. An index of factorial simplicity. Psychom 1974; 39:31-6.

22. Bartlett MS. The effect of standardization on a $x 2$ approximation in factor analysis. Biom 1951;38:337-44.

23. Mead MN. Benefits of sunlight: a bright spot for human health. National Institute of Environmental Health Sciences; 2008.

24. Cullum A, Ellis S, Leng G, Richardson J, Sheppard L. NICE public health guidance update. J Public Health (Oxf) 2017;39:213-4.

25. Altun İ, Çınar ND, Kaşıkçı MK. Self- reported quantity of daily water intake and urine output in healthy young. Int J Urol Nurs 2012;6:91-3.

26. Nissensohn M, Castro-Quezada I, Serra-Majem L. Beverage and water intake of healthy adults in some European countries. Int $\mathbf{J}$ Food Sci Nutr 2013;64:801-5.

27. Brunt H, Barnes J, Jones SJ, Longhurst JWS, Scally G, Hayes E. Air pollution, deprivation and health: understanding relationships to add value to local air quality management policy and practice in Wales, UK. J Public Health (Oxf) 2016;39:485-97.

28. Spurr K, Pendergast N, MacDonald S. Assessing the use of the Air Quality Health Index by vulnerable populations in a 'lowrisk' region: a pilot study. Can J Respir Ther 2014;50:45-9.

29. Johansson A, Windahl M, Svanborg E, Fredrichsen M, Swahn E, Uhlin PY, et al. Perceptions of how sleep is influenced by rest, activity and health in patients with coronary heart disease: a phenomenographical study. Scand J Caring Sci 2007;21:467-75.

30. Sharma KS, Srivastava SP, Panchal PA, Kaur AM. The effect of shift work on lifestyle, mental health and physical health status of footwear factory workers: a comparison between night shifts and day shifts. Indian J Physiother Occup Ther 2017;11:34-9.

31. Fujiki RB, Oliver AJ, Sivasankar MP, Craig BA, Malandraki GA. Secondary voice outcomes of a randomized clinical trial comparing two head/neck strengthening exercises in healthy older adults: a preliminary report. J Speech Lang Hear Res 2019; 62:318-23.

32. Cirer-Sastre R, Legaz-Arrese A, Corbi F, George K, Nie J, Carranza-García LE, et al. Cardiac biomarker release after exercise in healthy children and adolescents: a systematic review and meta-analysis. Pediatr Exerc Sci 2019;31:28-36.

33. Todde F, Melis F, Mura R, Pau M, Fois F, Magnani S, et al. A 12-week vigorous exercise protocol in a healthy group of persons over 65: study of physical function by means of the Senior Fitness Test. Biomed Res Int 2016. doi: 10.1155/2016/7639842.

34. Wisse W, Boer Rookhuizen M, de Kruif MD, van Rossum J, Jordans I, ten Cate $\mathrm{H}$, et al. Prescription of physical activity is not sufficient to change sedentary behavior and improve glycemic control in type 2 diabetes patients. Diabetes Res Clin Pract 2010;88:e10-3.

35. Fleig L, Kerschreiter R, Schwarzer R, Pomp S, Lippke S. 'Sticking to a healthy diet is easier for me when I exercise regularly': cognitive transfer between physical exercise and healthy nutrition. Psychol Health 2014;29:1361-72.

36. Sonchar CL. Medications alone are not the answer for an optimally functioning thyroid, instead healthy nutrition \& lifestyle choices are the keys! J Counc Nutr 2016;39:11-4.

37. Ward MM. Sense of control and self-reported health in a population-based sample of older Americans: assessment of potential confounding by affect, personality, and social support. Int J 
Behav Med 2013;20:140-7.

38. Fastame MC, Hitchcott PK, Penna MP. Does social desirability influence psychological well-being: perceived physical health and religiosity of Italian elders? A developmental approach. Aging Ment Health 2017;21:348-53.

39. Campos-Matos I, Subramanian SV, Kawachi I. The 'dark side' of social capital: trust and self-rated health in European countries. Eur J Public Health 2016;26:90-5.

40. Kremer H, Ironson G, Porr M. Spiritual and mind-body beliefs as barriers and motivators to HIV-treatment decision-making and medication adherence? A qualitative study. AIDS Patient Care STDS 2009;23:127-34.

41. Jensen MK, Chiuve SE, Rimm EB, Dethlefsen C, Tjønneland A, Joensen AM, et al. Obesity, behavioral lifestyle factors, and risk of acute coronary events. Circulation 2008;117:3062-9.

42. Franco OH, de Laet C, Peeters A, Jonker J, Mackenbach J, Nusselder W. Effects of physical activity on life expectancy with cardiovascular disease. Arch Intern Med 2005;165:2355-60.

43. Nunnally JC, Bernstein IH. Psychometric theory. 3rd ed. New York: McGraw-Hill; 1994. 